\title{
Alianças estratégicas colaborativas e o ambiente institucional-regulatório em empresas de biotecnologia - segmento saúde humana na região sul do Brasil
}

\author{
Collaborative strategic alliances and institutional and regulatory \\ environment in biotechnology companies - human health sector \\ in southern Brazil
}

\author{
Israel Ferreira Júnior ${ }^{1}$ \\ Andréa Paula Segatto ${ }^{1}$
}

\begin{abstract}
Resumo: A biotecnologia é um campo de conhecimento multidisciplinar que oferece oportunidades e incentivos para a formação de parcerias e alianças, principalmente para complementação de recursos. As empresas do segmento de saúde humana tendem a desenvolver relações com outras empresas, especialmente as da área química ou farmacêutica. Em muitos casos, as empresas de biotecnologia estabelecem interações visando lidar com questões regulatórias presentes na área de saúde humana. Os aspectos regulatórios se inserem dentro do ambiente institucional do setor, no qual devem existir condições que favoreçam o desenvolvimento das empresas de biotecnologia. Em decorrência disso, o presente trabalho constitui-se de uma pesquisa qualitativa que analisou a relação entre o ambiente institucional-regulatório em biotecnologia, segmento de saúde humana, e alianças estratégicas realizadas pelas empresas deste setor. Para tanto, foram realizados estudos de casos em empresas sediadas na região sul do Brasil, cujos resultados mostraram que as alianças estratégicas realizadas sofrem influência de elementos do ambiente institucional como a legislação de biossegurança, os direitos de patentes e as fontes de financiamentos; sendo que o nível de influência irá variar conforme a atividade realizada pela empresa, o perfil do parceiro de relacionamento e o tipo de acordo estabelecido.
\end{abstract}

Palavras-chave: Alianças estratégicas. Ambiente institucional. Regulação setorial. Biotecnologia. Saúde humana.

\begin{abstract}
Biotechnology is a multidisciplinary field of knowledge that provides opportunities and incentives for the formation of partnerships and alliances, especially to complement resources. The companies in the human health sector tend to develop relationships with other companies, especially from the chemical or pharmaceutical sectors. In many cases, biotechnology companies establish interactions in order to deal with regulatory issues of the human health sector. The regulatory aspects are inserted in the institutional environment of the sector, in which there must be conditions that favor the development of biotechnology companies. As a result, this paper describes a qualitative study of the relationship between the institutional and regulatory environment in biotechnology, a human health segment, and the strategic alliances created by the companies in this sector. The case studies were conducted in companies in southern Brazil. The results showed that the strategic alliances formed are influenced by institutional environment elements such as biosafety legislation, patent rights, and sources of funding, and the level of influence varies according to the company activity, the partner profile, and the type of agreement.
\end{abstract}

Keywords: Strategic alliances. Institutional environment. Sectoral regulation. Biotechnology. Human health.

\section{Introdução}

A biotecnologia é um campo de conhecimento multidisciplinar que envolve pesquisa básica e aplicada, com diferentes níveis tecnológicos e aplicações comerciais em diversos setores da economia, visto que seus produtos e processos podem ser utilizados em várias indústrias (SILVEIRA; POZ; FONSECA, 2002). Desse modo, dos diversos setores que se beneficiam do avanço do conhecimento em biotecnologia, os setores de agricultura e saúde são os apontados por Figueiredo, Penteado e Medeiros (2006) como aqueles que obtêm maior grau de benefícios.

A biotecnologia se caracteriza pelo alto grau de complexidade, altos custos de transação e incerteza ambiental, bem como pela dificuldade na

\footnotetext{
${ }^{1}$ Programa de Pós-Graduação em Administração - PPGADM, Universidade Federal do Paraná - UFPR, Av. Prefeito Lothário Meissner, 632, 2º andar, Jardim Botânico, CEP 80210-170, Curitiba, PR, Brasil, e-mail: isjunior99@yahoo.com.br; aps@ufpr.br
} 
previsão de sucesso na aplicação comercial de uma eventual descoberta. Nesse setor, as descobertas e avanços tecnológicos se encontram distribuídos, impossibilitando que, individualmente, as empresas possuam todos os recursos e capacidades necessárias para alcançar grandes resultados.

Assim, no que concerne ao desenvolvimento tecnológico, a biotecnologia é uma área que oferece oportunidades e incentivos para a formação de parcerias. Desta forma, as alianças externas se mostram uma necessidade e têm se configurado como uma alternativa viável e muito utilizada neste setor (AUDRETSCH; FELDMAN, 2003; PANGARKAR, 2003; ESTRELLA, 2008).

As empresas de biotecnologia do segmento de saúde humana tendem a estabelecer relações de cooperação com grandes empresas farmacêuticas ou químicas. Isto porque essas grandes empresas possuem um conjunto de competências mais amplas que as pequenas empresas de biotecnologia, tais como experiência em produção em larga escala, testes clínicos, marketing e distribuição (DAHLANDER; McKELVEY, 2005). Além disso, as empresas desse setor, muitas vezes, necessitam da expertise das grandes empresas para lidar com questões regulatórias, principalmente para aprovação de novas drogas e procedimentos na área de saúde humana.

Como a área de biotecnologia é extremamente dinâmica, é necessário que os marcos regulatórios acompanhem a evolução do conhecimento, de modo a não criarem barreiras que impeçam o desenvolvimento do setor. Entretanto, não é apenas a questão regulatória que deve estar em conformidade com as novas descobertas. Valle (2005) destaca que a biotecnologia moderna necessita que todo o ambiente institucional seja revisto de modo a se obter uma nova conjuntura de instituições que favoreçam o crescimento das empresas e o progresso do setor como um todo.

Esse ambiente institucional é composto pelas regras políticas, sociais e legais que fundamentam as atividades realizadas em biotecnologia, incluindo-se aqui a legislação específica e as políticas públicas de desenvolvimento do setor. Também fazem parte do ambiente institucional as instituições de educação e pesquisa, os órgãos governamentais de regulação e fomento, além das próprias empresas de biotecnologia.

Em vista do exposto, o objetivo do artigo é analisar a relação entre o ambiente institucional-regulatório e as alianças estratégicas colaborativas no setor de biotecnologia - segmento de saúde humana na região sul do Brasil.

Além desta introdução, o artigo é composto de uma revisão teórica que trata do ambiente institucionalregulatório em biotecnologia e de alianças estratégicas. Esta revisão possibilitou a identificação das categorias analíticas do estudo, as quais estão descritas na seção dos procedimentos metodológicos. Na sequência, são apresentados os resultados e as considerações finais do artigo.

\section{Referencial teórico}

\subsection{Biotecnologia}

Partindo de uma perspectiva genérica, a biotecnologia pode ser entendida como conjunto de tecnologias habilitadoras (enabling technologies) de base biológica, com possibilidades de aplicações em diversas áreas, tais como saúde humana, agricultura e manejo do meio ambiente (BIOMINAS, 2001; JUDICE; BAETA, 2005; VALLE, 2005; FIGUEIREDO; PENTEADO; MEDEIROS, 2006).

A biotecnologia também pode ser definida como

Os termos "indústria de biotecnologia" ou "bioindústria" são empregados para definir a aplicação em escala industrial e empresarial das tecnologias e avanços científicos oriundos do campo da pesquisa biológica na geração de produtos e serviços em diversas áreas. Por ser uma área em que a inovação é fundamental, na indústria de biotecnologia, os produtos e serviços possuem alto valor agregado, exigindo mão de obra qualificada (JUDICE; BAETA, 2005; CUNHA; MELO, 2006; BIOMINAS, 2007; ESTRELLA, 2008).

O desenvolvimento da biotecnologia impacta diferentes atividades industriais, mas os setores que mais se beneficiam são a agricultura e a área de saúde. A indústria de sementes e a indústria farmacêutica necessitam de inovações para se manterem competitivas, o que reflete na absorção dos conhecimentos oriundos da biotecnologia (FIGUEIREDO; PENTEADO; MEDEIROS, 2006).

Conforme a Fundação Biominas (2009), as empresas que atuam no segmento de saúde humana desenvolvem e comercializam kits de diagnóstico, vacinas, proteínas recombinantes, anticorpos, próteses, dispositivos e equipamentos médicos especializados, terapias celulares, curativos e peles artificiais. Elas também desenvolvem atividades para identificação de novas moléculas e fármacos, bem como a validação de novos medicamentos (ensaios pré-clínicos e clínicos), biossensores, metodologias avançadas de reprodução assistida etc.

Para Silveira, Poz e Fonseca (2002), a biotecnologia em saúde e medicamentos engloba instituições públicas e empresas privadas que pesquisam, produzem e comercializam produtos biotecnológicos, bem como desenvolvem atividades produtivas ligadas ao setor farmacêutico. A biotecnologia empregada neste setor faz uso de micro-organismos geneticamente modificados na produção de proteínas que são utilizadas no lugar de produtos de origem química ou extrativa quando estes se mostram ineficientes, inseguros ou mais complicados.

As primeiras empresas de biotecnologia, também chamadas de novas empresas de biotecnologia ou empresas dedicadas de biotecnologia, surgiram a 
partir de meados dos anos 1970, acompanhando o desenvolvimento do setor (AZEVEDO et al., 2002; BORGES, 2003; CHIESA; TOLETTI, 2004; VALLE, 2005; VÁZQUEZ; MARTÍN; MASCAREÑAS, 2006). De acordo com a Organização para a Cooperação e Desenvolvimento Econômico (ORGANISATION..., 2009), uma empresa de biotecnologia pode ser definida como aquela que utiliza pelo menos uma técnica biotecnológica para a produção de bens ou serviços e/ou para realizar pesquisa e desenvolvimento em biotecnologia.

Grande parte das empresas de biotecnologia teve início com cientistas acadêmicos, a partir de resultados de pesquisas, com apoio de universidades, fundos de investimentos de capital, programas governamentais, fundações de amparo à pesquisa e empresas farmacêuticas. Estas empresas surgiram com o objetivo de explorar comercialmente novas e promissoras tecnologias (ROIJAKKERS; HAGEDOORN, 2006; CHANG, 2008).

$\mathrm{O}$ apoio ao desenvolvimento das empresas de biotecnologia se deu por meio da provisão de recursos críticos e pelo desenvolvimento de um ambiente institucional que possibilitasse a comercialização das ciências da vida (VALLE, 2005; EBERS; POWELL, 2007; ESTRELLA, 2008).

De acordo com Valle (2005), ao longo do seu desenvolvimento, as empresas iniciantes tiveram que enfrentar, e ainda enfrentam dificuldades e problemas de ordem técnico-científica, financeira e institucional. As limitações de ordem técnico-científica decorrem do fato de a biotecnologia ser um campo do conhecimento ainda em construção e de grande complexidade, sendo natural surgirem alguns entraves desse tipo. As empresas enfrentam dificuldades financeiras em virtude do tempo relativamente longo para o lançamento de um produto, o qual gira em torno de 10 a 15 anos. Além do período longo para retorno, os investidores temem investir recursos também devido ao alto grau de incerteza do campo. Por fim, as empresas enfrentam problemas pelo fato de não dominarem ativos complementares na área de gestão (comercial, marketing, produção etc.) e dificuldades de lidar com as questões institucionais, como falhas no regime de propriedade intelectual e marco regulatório restritivo com relação aos produtos derivados da biotecnologia.

Considerando apenas a área de saúde humana, verifica-se a existência de grande proximidade deste segmento da biotecnologia com o setor farmacêutico. As interações resultantes foram fundamentais para o surgimento de empresas de biotecnologia e ainda continuam sendo importantes no desenvolvimento dos dois setores.

A biotecnologia trouxe avanços no modo como os remédios são descobertos, desenvolvidos e produzidos. Enquanto as empresas tradicionais utilizam uma estrutura farmacêutica baseada em química, novas empresas entrantes fazem uso das novas técnicas biotecnológicas (VÁZQUEZ; MARTÍN; MASCAREÑAS, 2006).

Uma característica marcante da indústria de biotecnologia que desenvolve aplicações na área de saúde humana é o pesado processo regulatório existente, principalmente no que se refere aos medicamentos. A aprovação de um novo medicamento por parte das agências regulatórias é algo que só ocorre após rigorosa análise e testes, demandando tempo e, consequentemente, grandes somas de recursos financeiros. A concepção, patenteamento, desenvolvimento, testes e aprovação regulatória e comercialização de um novo produto leva em média cerca de dez anos (OLIVER, 2001; ESTRELLA, 2008).

Existe uma forte complementaridade de recursos entre as grandes empresas farmacêuticas e as empresas de biotecnologia. No entendimento de Audretsch e Feldman (2003), as empresas farmacêuticas reconhecem que estabelecer relacionamentos para obter novos produtos biotecnológicos do que produzi-los internamente pode ser uma estrutura mais eficiente.

Do ponto de vista das novas empresas de biotecnologia, estas possuem ideias e produtos inovadores, mas, frequentemente, não têm os recursos necessários para completar o seu ciclo econômico. Dessa forma, os arranjos colaborativos com empresas farmacêuticas aparecem como uma solução viável. Embora tenham competências únicas e importantes para o ambiente competitivo, as empresas de biotecnologia enfrentam desafios por conta de suas limitações. Elas enfrentam problemas em obter fontes de financiamento ou não têm expertise administrativa, pois, muitas vezes, o foco dessas empresas se encontra mais nas questões tecnológicas do que nas gerenciais (VÁZQUEZ; MARTÍN; MASCAREÑAS, 2006).

\subsection{Ambiente institucional-regulatório em biotecnologia}

O desenvolvimento do campo da biotecnologia, com o surgimento de novas áreas de pesquisa e aplicações, torna cada vez maior a necessidade de revisão e elaboração de marcos regulatórios e institucionais, que incluam diferentes questões, como legislação referente aos organismos geneticamente modificados, pesquisas e estudos com células-tronco embrionárias, utilização de técnicas de clonagem para fins terapêuticos, acesso a recursos genéticos, normas de biossegurança e direitos de propriedade intelectual. As novas tecnologias afetam não apenas as questões normativas e regulatórias, mas todo o ambiente institucional em que a biotecnologia está inserida (POSSAS, 2004; VALLE, 2005). 
Antes de qualquer consideração sobre o marco regulatório e o ambiente institucional no setor de biotecnologia, faz-se necessário entender o conceito de instituição (VALLE, 2005). Para Scott (2008, p.48), as Em virtude do foco deste trabalho, maior foco será dado ao caráter regulativo das instituições.

Considerando o aspecto regulativo, constata-se que as instituições limitam e regularizam o comportamento. O processo regulatório é composto de três atividades centrais: definição de regras, monitoramento e aplicação de regras. $\mathrm{O}$ aspecto regulativo das instituições está relacionado com a capacidade de estabelecer regras, verificar a conformidade de ação em relação a elas e, caso seja necessário, administrar sanções (recompensas ou punições) como forma de estimular ou limitar o comportamento (SCOTT, 2008).

De acordo com Dosi e Orsenigo (1988), as instituições também podem se referir ao conjunto de organizações formais que, num sentido mais estrito, são exemplificadas pelas empresas, universidades, institutos de pesquisa e agências governamentais.

O conceito de instituições é fundamental para a compreensão da dinâmica existente em um determinado setor, pois é no ambiente institucional que são elaboradas as regras e exigências às quais uma organização deve atender se ela desejar receber apoio e alcançar legitimidade, condições necessárias para a sobrevivência e crescimento.

Ampliando a perspectiva de análise, Davis e North (1971 apud WILLIAMSON, 1994) consideram o ambiente institucional como o conjunto de regras políticas, sociais e legais que estabelecem as bases para a produção, comércio e distribuição. Ainda segundo esses autores, um arranjo institucional consiste num acordo entre as unidades econômicas que delimita as formas em que estas unidades podem colaborar e/ou competir. Tais arranjos influenciam mudanças nas leis ou nos direitos de propriedade.

De acordo com Kaiser (2003), quatro indicadores podem ser utilizados para a avaliação de um ambiente institucional, especialmente de setores como o de biotecnologia. Os indicadores são: a estrutura de regulação setorial, as políticas públicas de $\mathrm{P} \& \mathrm{D}$ e inovação, o sistema de financiamento e o sistema de pesquisa e inovação.

Tendo por base as definições apresentadas, pode-se considerar que o ambiente institucional em que se desenvolve o campo da biotecnologia é composto por empresas, universidades, institutos de pesquisa, agências de fomento, órgãos e entidades responsáveis pela regulação e fiscalização das atividades realizadas, como a Agência Nacional de Vigilância Sanitária (ANVISA), o Conselho Nacional de Biossegurança (CNBS) e a Comissão Técnica Nacional de Biossegurança (CTNBio).

Visto que o aspecto regulativo é um dos pilares das instituições (SCOTT, 2008), quando se considera o ambiente institucional em biotecnologia, é importante considerar o marco regulatório do setor, pois as atividades realizadas nesse campo devem obedecer às definições legais. Desse modo, a regulação setorial se constitui em elemento fundamental na análise do ambiente institucional em biotecnologia.

No que concerne às questões de regulação relacionadas ao campo da biotecnologia, atualmente são fundamentais a delimitação dos direitos de propriedade intelectual e a das normas de biossegurança, que buscam prevenir possíveis efeitos prejudicais das novas tecnologias sobre a saúde humana e meio ambiente (POSSAS, 2004; VALLE, 2005).

Nos últimos anos, o governo brasileiro tomou algumas medidas no que diz respeito à regulamentação visando ao desenvolvimento do campo da biotecnologia. De modo geral, cabe destacar a tentativa de criação de um quadro regulatório das atividades que estão relacionadas com a biotecnologia moderna. $\mathrm{O}$ estabelecimento de um marco regulatório adequado é fundamental para a criação de um ambiente institucional propício para a realização de investimentos no setor (SILVEIRA et al., 2004). Quanto à legislação, destacam-se: a Política de Desenvolvimento de Biotecnologia (Decreto 6.041/07) (BRASIL, 2007); a Lei de Biossegurança (Lei 11.105/05) (BRASIL, 2005); e a Lei de Propriedade Industrial e Patente (Lei 9.279/96) (BRASIL, 1996).

No Brasil, a questão da biossegurança é disciplinada pela Lei n ${ }^{\circ} 11.105$ de 24 de março de 2005 (BRASIL, 2005). Entre outras questões, esta lei estabelece as normas de segurança e mecanismos de fiscalização de atividades que envolvam mecanismos geneticamente modificados e seus derivados. Esta lei também cria o Conselho Nacional de Biossegurança - CNBS e reestrutura a Comissão Técnica Nacional de Biossegurança - CTNBio, além de tratar da Política Nacional de Biossegurança - PNB (BRASIL, 2005).

Além da CTNBio, que trata das questões de biossegurança, cabe destacar o papel desempenhado pela Agência Nacional de Vigilância Sanitária - ANVISA na regulação setorial e fiscalização de atividades relacionadas à biotecnologia, especialmente no que diz respeito à área de saúde humana. A ANVISA tem sob sua responsabilidade o registro de medicamentos, a concessão de autorização para funcionamento dos laboratórios farmacêuticos e outras empresas da cadeia farmacêutica, bem como a regulação dos ensaios clínicos. Ela também está encarregada de analisar pedidos de patentes de produtos e processos farmacêuticos, atuando de forma conjunta com o Instituto Nacional de Propriedade Industrial (INPI).

A área de fármacos ou produtos relacionados à saúde humana ou animal é uma das mais atrativas para os depósitos em biotecnologia, sendo, nesta área, o foco dos maiores investimentos em pesquisa $\mathrm{e}$ 
desenvolvimento. De acordo com pesquisa realizada por Figueiredo, Penteado e Medeiros (2006), no Brasil, verifica-se uma tendência maior de proteção na área de biotecnologia farmacológica e biotecnologia agrícola.

As patentes permitem que as empresas protejam suas inovações, possibilitando a obtenção do retorno financeiro dos investimentos realizados. Os recursos financeiros obtidos pelas empresas inovadoras constituem uma fonte interna para a realização de novos investimentos em pesquisa e desenvolvimento. Mas nem sempre as fontes internas são suficientes, visto que as empresas possuem outras necessidades, por exemplo, capital de giro para continuarem funcionando. Assim, torna-se imprescindível a existência de outras fontes de financiamento.

Empresas de base tecnológica, como é o caso das empresas de biotecnologia, normalmente encontram dificuldades em obter recursos no mercado financeiro, pois este trabalha com uma lógica conservadora e buscando retornos no curto prazo. Quando existe capital disponível, este é investido em etapas mais avançadas do processo de inovação, nas quais os riscos se encontram reduzidos. Paradoxalmente, muitas empresas de base tecnológica carecem de recursos para serem aplicados nas fases iniciais de um projeto inovador ou mesmo de seu desenvolvimento. Tal realidade mostra a necessidade da existência de alternativas, como fontes públicas de financiamento (SILVEIRA et al., 2004; CORDER; SALLES-FILHO, 2006).

Para financiar suas atividades, as empresas de base tecnológica podem obter recursos financeiros se beneficiando de três possibilidades oferecidas pelas entidades governamentais: recursos subvencionados, que não são reembolsáveis; recursos reembolsáveis, que envolvem programas de financiamento com prazos e taxas especiais; recursos oriundos de capital de risco (venture capital e private equity), cuja utilização também possui apoio governamental (MAÇANEIRO; CHEROBIM, 2011).

As principais agências públicas, na esfera federal, que disponibilizam recursos financeiros para tecnologia e inovação são o Banco Nacional de Desenvolvimento Econômico e Social (BNDES), o Conselho Nacional de Desenvolvimento Científico e Tecnológico (CNPq) e a Financiadora de Estudos e Projetos (FINEP). Em nível estadual, a oferta de crédito é bem limitada, ficando geralmente a cargo das fundações de amparo à pesquisa de cada estado.

Embora existam atualmente diversas opções de financiamento público, as empresas de biotecnologia têm buscado alternativas, isto é, obter recursos com outras empresas. Esta estratégia é utilizada como forma de superar não apenas as restrições financeiras, mas também limitações de outra natureza. No segmento de saúde humana, as empresas de biotecnologia utilizam como estratégia as parcerias e alianças colaborativas.

\subsection{Alianças estratégicas colaborativas}

As alianças estratégicas são arranjos colaborativos que envolvem trocas, compartilhamento ou desenvolvimento conjunto de produtos, tecnologias ou serviços, nas quais cada parceiro pode contribuir com capital, tecnologia, bens específicos ou conhecimento. Uma das principais motivações para a união das empresas é o aprendizado, que implica na transferência e absorção de conhecimento dos parceiros para explorar novos conhecimentos ou explorar complementaridades (CUNHA; MELO, 2005; ZHANG; BADEN-FULLER; MANGEMATIN, 2007).

As alianças estratégicas possibilitam a combinação de capacidades e recursos específicos entre empresas diferentes para o alcance de objetivos comuns. A colaboração também pode ser utilizada na busca de objetivos distintos entre as duas empresas, mas que só podem ser alcançados por meio da complementaridade de recursos, como é o caso das relações entre grandes empresas farmacêuticas e as pequenas e médias empresas de biotecnologia (VÁZQUEZ; MARTÍN; MASCAREÑAS, 2006).

As alianças podem ser classificadas, de acordo com Prevezer e Toker (1996), em: acordos de licenciamento; acordos de marketing; contratos de pesquisa; participação acionária; joint-ventures.

As licenças conferem o direito de produzir ou comercializar produtos específicos derivados de biotecnologia ou o direito de utilizar uma tecnologia. Pode ocorrer de modo exclusivo ou não exclusivo, com o licenciador recebendo royalties pela cessão de direitos (PREVEZER; TOKER, 1996).

Acordos de mercado (marketing) são mais comuns de ocorrer entre pequenas empresas de biotecnologia, que atuam em pesquisas, e as grandes empresas, que possuem canais de mercado e distribuição já estabelecidos. Acordos desse tipo permitem que uma empresa entre em um mercado e distribua seus produtos em uma área específica, fazendo uso dos canais de outra empresa (PREVEZER; TOKER, 1996).

Os contratos de pesquisa englobam os relacionamentos formais que têm como alvo a pesquisa em uma tecnologia específica ou em áreas de aplicações. São parcerias contratuais que regulam a cooperação de $\mathrm{P} \& \mathrm{D}$, em que um parceiro, normalmente a grande empresa, contrata outro parceiro, geralmente a pequena empresa, para desenvolver uma tecnologia específica. Nos contratos de pesquisa, são definidos os seguintes pontos: o resultado desejado da pesquisa; a atribuição dos direitos de propriedade; a divisão de responsabilidades; e a comercialização (PREVEZER; TOKER, 1996; ROIJAKKERS; HAGEDOORN, 2006).

Existem também os acordos para $\mathrm{P} \& \mathrm{D}$ em conjunto, nos quais os recursos de duas ou mais empresas são reunidos com o objetivo de compartilhar know-how 
tecnológico e estabelecem programas conjuntos para P\&D (ROIJAKKERS; HAGEDOORN, 2006).

A participação acionária envolve certos direitos de propriedade de uma empresa sobre outra, normalmente de uma grande empresa sobre uma empresa emergente. Existe também a participação minoritária, que é um tipo de parceria de $\mathrm{P} \& \mathrm{D}$, em que um parceiro de pesquisa obtém pequeno interesse (menos de $50 \%$ ) na outra empresa. Esses tipos de arranjos são tipicamente combinados com acordos de troca de tecnologia, o que dá aos parceiros a oportunidade de explorar novas e promissoras tecnologias sem a alocação de grandes quantidades de recursos (PREVEZER; TOKER, 1996; ROIJAKKERS; HAGEDOORN, 2006).

A joint-venture envolve a formação de uma nova companhia independente, de propriedade compartilhada entre os parceiros de aliança. A criação de uma nova empresa envolve considerável interação entre as duas empresas criadoras, principalmente com relação aos objetivos conjuntos e formas de alcançá-los. Este tipo de acordo tem o propósito de reduzir os custos de transação entre parceiros de pesquisa independentes (PREVEZER; TOKER, 1996; ROIJAKKERS; HAGEDOORN, 2006).

Os acordos existentes entre empresas de biotecnologia e as empresas farmacêuticas podem, de acordo com Chang (2008), ser divididos entre relacionados à $\mathrm{P} \& \mathrm{D}$ e não relacionados à $\mathrm{P} \& \mathrm{D}$. $\mathrm{O}$ segundo tipo envolve acordos de marketing, produção, distribuição e joint-venture não relacionadas com $\mathrm{P} \& \mathrm{D}$.

Os arranjos colaborativos podem ocorrer, com maior frequência, entre grandes empresas farmacêuticas e pequenas e médias empresas de biotecnologia que estão desenvolvendo produtos farmacêuticos. Entretanto, as empresas de biotecnologia, independente do porte, podem realizar parcerias estratégicas de pesquisa e estabelecer relacionamentos com outras semelhantes, com cientistas envolvidos com essas empresas ou atuantes no setor, com universidades e institutos de pesquisa, e com grandes empresas de outros setores, por exemplo, químico (AUDRETSCH; FELDMAN, 2003).

Em um setor de rápido desenvolvimento tecnológico, como é o de biotecnologia, as descobertas estão distribuídas entre diferentes atores, impossibilitando que uma empresa possua todas as capacidades necessárias para o sucesso. Novas tecnologias conduzem e, ao mesmo tempo, exigem uma variedade de esforços colaborativos entre as empresas de biotecnologia e outros atores com os objetivos de aumentar o aprendizado, reduzir as incertezas inerentes e associadas a novos produtos $\mathrm{e}$ mercados, bem como acessar recursos complementares e conhecimento (POWELL; KOPUT; SMITHDOERR, 1996; DAHLANDER; McKELVEY, 2005).

Em virtude da difusão do conhecimento em biotecnologia, as parcerias das empresas ocorrem com outros atores, como universidades e institutos de pesquisa. As ações conjuntas contribuem para o desenvolvimento da ciência e de novas tecnologias, possibilitando a inovação e a comercialização posterior no campo da biotecnologia. Além disso, o relacionamento com instituições de ensino e pesquisa fornece mão de obra qualificada, novas ideias de pesquisa, bem como acesso a testes clínicos (DAHLANDER; McKELVEY, 2005).

Em seu estudo sobre a colaboração interorganizacional em biotecnologia, Powell, Koput e Smith-Doerr (1996) apresentam os principais tipos de acordos realizados no setor. Os acordos em biotecnologia e os parceiros envolvidos podem ser vistos no Quadro 1.

Para as empresas de pequeno porte, uma parceria ou aliança pode ser a alternativa para superar desvantagens relacionadas ao tamanho (AUDRETSCH; FELDMAN, 2003). As pequenas empresas também necessitam de capital e de outras capacidades possuídas pelas grandes empresas, tais como: (1) expertise e conhecimento para lidar com questões regulatórias; (2) competência para conduzir testes clínicos em tempo adequado; (3) habilidade para produzir em escala e em grandes quantidades; e (4) capacidades de distribuição e o mercado estabelecido.

\section{Procedimentos metodológicos}

A abordagem escolhida para este estudo é a qualitativa. Com base nos objetivos, a pesquisa que fundamenta o artigo é considerada descritiva, pois busca descrever o fenômeno alianças estratégicas à luz do ambiente institucional-regulatório em biotecnologia, segmento de saúde humana.

A estratégia de pesquisa utilizada foi o estudo comparativo de casos. Einsenhardt (1989) considera o estudo de caso como uma estratégia para a compreensão das dinâmicas presentes dentro de ambientes únicos. Além disso, a escolha da estratégia de estudo de caso se mostrou a mais adequada para a presente pesquisa em virtude do número reduzido de empresas constituintes da população alvo da investigação.

No que se refere ao horizonte de tempo, a pesquisa realizada se enquadra como sendo do tipo transversal (cross-sectional), mas também com uma perspectiva longitudinal. Tal classificação decorre do fato de que o fenômeno objeto da pesquisa pode ser constituído por eventos ocorridos anteriormente ao período de realização da investigação.

Considerou-se como população a ser alvo desta pesquisa as empresas de biotecnologia que atuem no segmento de saúde humana, sediadas na região sul do Brasil e que possuam alianças estratégicas colaborativas. Os casos foram escolhidos de acordo com critérios não probabilísticos, isto é, por intencionalidade e por adesão. A intencionalidade se referiu à existência de alianças estratégicas 
colaborativas. Já o critério de adesão foi relativo à aceitação ou não das empresas em participar da pesquisa.

$\mathrm{Na}$ identificação das empresas de biotecnologia sediadas no sul do Brasil e atuantes no segmento de saúde humana, foi utilizado o último diretório de empresas de biociências elaborado pela Fundação Biominas (BIOMINAS, 2009) e o Portal da Inovação, mantido pelo Ministério de Ciência e Tecnologia (BRASIL, 2011). Não foram identificadas empresas de biotecnologia da área de saúde humana no Estado de Santa Catarina. As empresas estudadas estão apresentadas no Quadro 2 a seguir:

Os dados primários foram coletados por meio de entrevistas, com roteiro semiestruturado, realizadas com dirigentes-proprietários das empresas. A observação não participante também se constituiu em outra fonte de dados primários. Os dados secundários foram obtidos a partir de material institucional de divulgação, tais como folders, panfletos e sítios eletrônicos. A utilização das diferentes fontes permitiu a triangulação dos dados.

A análise dos dados coletados foi feita de modo predominantemente qualitativo, por meio da técnica de análise de conteúdo. De acordo com Laville e
Dionne (1999), na análise de conteúdo qualitativa busca-se interpretar o significado de um conteúdo, à luz de categorias analíticas definidas previamente.

As categorias analíticas definidas, com base na revisão de literatura, para este estudo foram: 1) alianças estratégicas colaborativas; 2) ambiente institucionalregulatório; 3) regulação setorial (legislação de biossegurança e patentes); 4) fontes de financiamento. A relação entre as categorias pode ser visualizada no modelo de pesquisa representado pela Figura 1:

Para auxiliar o processo de análise dos dados, utilizou-se o software NVIVO 9, que é específico para análises qualitativas. No uso do NVIVO, as categorias analíticas definidas previamente foram identificadas como os nós (nodes), ajudando na codificação das informações coletadas, facilitando o processo de interpretação das relações encontradas.

\section{Resultados}

\subsection{Caso 1 - Empresa Alfa}

A empresa Alfa iniciou suas atividades em julho de 2003. A empresa se estabeleceu no mercado

Quadro 1. Acordos colaborativos em biotecnologia.

\begin{tabular}{|l|l|l|}
\hline \multicolumn{1}{|c|}{ Tipo de acordo } & \multicolumn{1}{|c|}{ Descrição } & \multicolumn{1}{c|}{ Parceiros } \\
\hline Pesquisa e Desenvolvimento & $\begin{array}{l}\text { Empresa de biotecnologia desenvolve } \\
\text { programa de pesquisa com outra } \\
\text { organização com um objetivo específico. }\end{array}$ & $\begin{array}{l}\text { Empresas de biotecnologia, } \\
\text { empresas farmacêuticas, } \\
\text { institutos de pesquisa, } \\
\text { laboratórios universitários. }\end{array}$ \\
\hline Venture Capital Investidor Externo & $\begin{array}{l}\text { Obtenção de recursos de fundos de } \\
\text { investimento ou fundos governamentais. }\end{array}$ & $\begin{array}{l}\text { Empresas de venture capital, } \\
\text { agências públicas de fomento. }\end{array}$ \\
\hline Testes Clínicos / Avaliação & $\begin{array}{l}\text { Empresa de biotecnologia possui parceiro } \\
\text { para conduzir testes clínicos e avaliação } \\
\text { do produto, de acordo com as agências } \\
\text { regulatórias. }\end{array}$ & $\begin{array}{l}\text { Hospitais, empresas } \\
\text { especializadas em testes } \\
\text { clínicos. }\end{array}$ \\
\hline Manufatura & $\begin{array}{l}\text { Empresa de biotecnologia subcontrata } \\
\text { parceiro para produção de seu produto. }\end{array}$ & $\begin{array}{l}\text { Empresas farmacêuticas, } \\
\text { empresas químicas. }\end{array}$ \\
\hline Licenciamento / Comercialização & $\begin{array}{l}\text { Empresa de biotecnologia licencia nova } \\
\text { ideia para a comercialização. }\end{array}$ & Empresas farmacêuticas. \\
\hline Aquisição de Direitos & $\begin{array}{l}\text { Empresa de biotecnologia adquire direitos } \\
\text { de nova ideia ou patente. }\end{array}$ & Universidades. \\
\hline Suprimentos / Distribuição & $\begin{array}{l}\text { Acordos para receber materiais ou fornecer } \\
\text { produtos para distribuidores. }\end{array}$ & $\begin{array}{l}\text { Grandes empresas químicas e } \\
\text { farmacêuticas. }\end{array}$ \\
\hline Investimento / Joint Venture & $\begin{array}{l}\text { Empresa investe capital financeiro, capital } \\
\text { humano ou capital científico. }\end{array}$ & $\begin{array}{l}\text { Outras empresas de } \\
\text { biotecnologia. }\end{array}$ \\
\hline Acordos Complexos & $\begin{array}{l}\text { Acordos que envolvem mais de um acordo } \\
\text { dos listados anteriormente. }\end{array}$ & $\begin{array}{l}\text { Qualquer parceiro, exceto } \\
\text { empresas de venture capital. }\end{array}$ \\
\hline
\end{tabular}

Fonte: Powell, Koput e Smith-Doerr (1996).

Quadro 2. Empresas de biotecnologia pesquisadas.

\begin{tabular}{|c|c|c|c|}
\hline Caso & Empresa & Área de atuação principal & Localidade \\
\hline 1 & Alfa & Produção de indicadores biológicos & Campo Mourão - PR \\
\hline 2 & Beta & Pesquisa e desenvolvimento de moléculas & Porto Alegre - RS \\
\hline
\end{tabular}




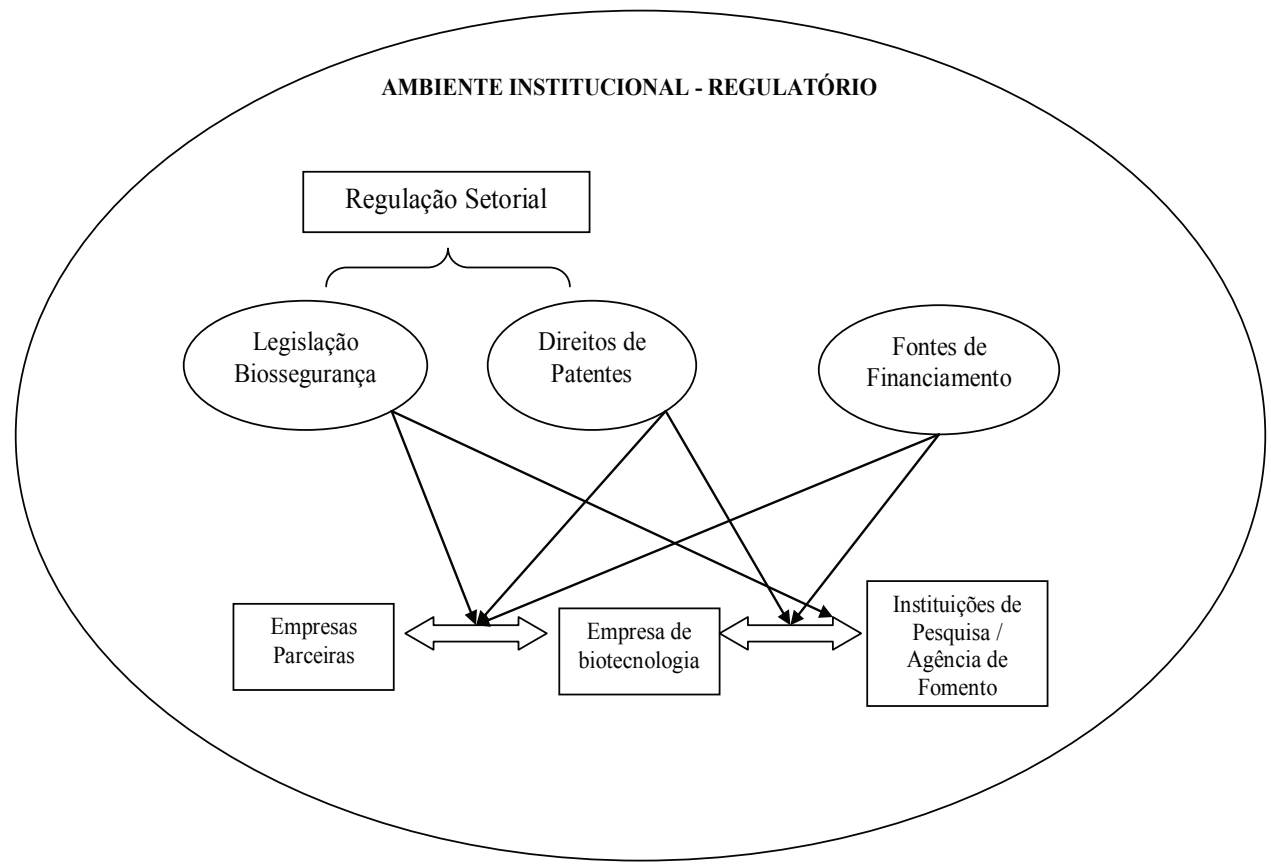

Figura 1. Modelo de pesquisa. Fonte: elaborado pelo autor.

tendo como objetivo fabricar e distribuir e serviços voltados à área de biossegurança, fazendo uso de avançadas técnicas em biotecnologia. $\mathrm{O}$ conceito que norteia a empresa é o desenvolvimento de produtos e processos biotecnológicos para a área da saúde. $\mathrm{O}$ principal produto da empresa é o indicador biológico para monitoração de esterilização a vapor e a óxido de etileno de produtos médicos-odontológicos, por exemplo, autoclaves.

\subsubsection{Alianças estratégicas}

De modo geral, quando se trata de alianças estratégicas, a Alfa possui relacionamentos com três grupos de instituições: empresas privadas, que representam $70 \%$ das parcerias; agências de fomento e instituições de apoio, que representam $20 \%$ das interações; e universidades e institutos de pesquisa, representando $10 \%$ dos relacionamentos. As principais parcerias da empresa Alfa estão sintetizadas no Quadro 3 a seguir:

\subsubsection{Ambiente institucional-regulatório}

A empresa não tem nenhum tipo de patente para proteger o seu processo produtivo. Por uma questão estratégica, não é interessante para a empresa patentear visando não abrir o seu processo produtivo.

Considerando que o principal produto da Alfa é o indicador biológico, verificou-se que a empresa não precisa de nenhum tipo de registro ou cadastro desse produto na ANVISA. Apesar disso, a Alfa possui registro e, para desenvolver suas atividades, teve que atender a todas às exigências da ANVISA, por exemplo, em questões de instalações. A autorização de funcionamento da empresa concedida pela ANVISA é para a fabricação de produtos correlatos para a área da saúde.

De forma mais específica, considerando a legislação de biossegurança, a empresa apenas necessita justificar a utilização da cepa importada como insumo para a produção de produto, o qual não traz risco algum a saúde pública, nem risco algum ao manipulador.

Desde o início de suas atividades, a Alfa tem financiado suas atividades de pesquisa e desenvolvimento por meio de recursos obtidos de programas públicos de financiamento, como são os recursos disponibilizados pelos editais da FINEP, CNPq, SEBRAE, por exemplo. À medida que a empresa foi crescendo, a proporção de recursos obtidos por meio da venda de produtos também foi aumentando.

Uma das fontes de recursos da empresa advém das compras públicas, por meio das licitações governamentais. Assim, mesmo que de forma indireta, políticas públicas acabam afetando a empresa.

\subsection{Caso 2 - Empresa Beta}

A Beta é uma empresa de pesquisa biomédica, cujo foco de atuação se encontra na descoberta e desenvolvimento de fármacos e terapias inovadoras que podem ser utilizadas em diversas áreas clínicas, tais como psiquiatria, neurologia, oncologia e doenças 
Quadro 3. Síntese das principais características das alianças da empresa Alfa.

\begin{tabular}{|c|c|c|c|}
\hline Parcerias & Empresa privada & $\begin{array}{l}\text { Agência de fomento / } \\
\text { Instituição de apoio }\end{array}$ & \begin{tabular}{|c|}
$\begin{array}{c}\text { Universidades e Institutos } \\
\text { de pesquisa }\end{array}$ \\
\end{tabular} \\
\hline $\begin{array}{l}\text { Descrição do } \\
\text { parceiro }\end{array}$ & $\begin{array}{l}\text { Empresa que atua na área } \\
\text { de equipamentos para } \\
\text { biossegurança }\end{array}$ & $\begin{array}{l}\text { Financiadora de Estudos e } \\
\text { Projetos - FINEP }\end{array}$ & $\begin{array}{l}\text { Universidade } \\
\text { Tecnológica Federal do } \\
\text { Paraná - Campus de } \\
\text { Campo Mourão } \\
\end{array}$ \\
\hline Tipo de parceria & Suprimentos / Distribuição & $\begin{array}{l}\text { Venture Capital / Investidor } \\
\text { Externo }\end{array}$ & $\begin{array}{l}\text { Pesquisa e } \\
\text { Desenvolvimento }\end{array}$ \\
\hline Papel da Alfa & $\begin{array}{l}\text { Fornecimento de produtos e } \\
\text { revenda de produtos do parceiro }\end{array}$ & $\begin{array}{l}\text { Desenvolvimento de novo } \\
\text { produto (indicador biológico) }\end{array}$ & $\begin{array}{l}\text { Participação nos grupos de } \\
\text { pesquisa }\end{array}$ \\
\hline $\begin{array}{l}\text { Papel do } \\
\text { parceiro }\end{array}$ & $\begin{array}{l}\text { Distribuição e comercialização } \\
\text { dos produtos da Alfa }\end{array}$ & $\begin{array}{l}\text { Financiamento público não } \\
\text { reembolsável }\end{array}$ & $\begin{array}{l}\text { Realização de projetos de } \\
\text { P\&D para novos produtos } \\
\text { e validação de produtos } \\
\text { existentes }\end{array}$ \\
\hline $\begin{array}{l}\text { Recursos } \\
\text { disponibilizados }\end{array}$ & $\begin{array}{l}\text { Alfa: produtos } \\
\text { Parceiro: recursos comerciais e } \\
\text { logísticos }\end{array}$ & $\begin{array}{l}\text { Alfa: recursos de P\&D } \\
\text { Parceiro: recursos financeiros }\end{array}$ & $\begin{array}{l}\text { Alfa: recursos de P\&D } \\
\text { Parceiro: Recursos de P\&D } \\
\text { e infraestrutura }\end{array}$ \\
\hline Tipo de contrato & Formal & Formal & Formal e informal \\
\hline $\begin{array}{l}\text { Motivação } \\
\text { básica para a } \\
\text { parceria }\end{array}$ & $\begin{array}{l}\text { Utilização de canais de } \\
\text { distribuição já estabelecidos }\end{array}$ & $\begin{array}{l}\text { Obtenção de recursos financeiros } \\
\text { para desenvolvimento de novos } \\
\text { produtos }\end{array}$ & $\begin{array}{l}\text { Acesso a recursos e } \\
\text { infraestrutura para pesquisa } \\
\text { e desenvolvimento }\end{array}$ \\
\hline
\end{tabular}

Fonte: dados da pesquisa.

inflamatórias. A empresa surgiu em meados de 2008, sendo selecionada para ser integrante do Centro de Biotecnologia da Universidade Federal do Rio Grande do Sul (UFRGS), onde permanece incubada até os dias atuais.

\subsubsection{Alianças estratégicas}

A Beta é uma empresa com relativamente pouco tempo de existência, começou suas atividades em 2008, o que pode justificar não terem sido encontradas muitas alianças estabelecidas pela empresa. Embora existam possibilidades de novos relacionamentos, foram identificadas três alianças formais, conforme apresentado no Quadro 4 a seguir:

\subsubsection{Ambiente institucional-regulatório}

Com relação às patentes e propriedade intelectual, a questão de legislação tem uma grande influência nas que estão relacionadas às parcerias desenvolvidas pela Beta e que envolvem a universidade. Isto porque a divisão de propriedade intelectual com a universidade tem suas características e exigências próprias.

Como a atividade principal da empresa é atuar na pesquisa e desenvolvimento de moléculas, as regulações da ANVISA não têm influências nas atividades da Beta, nem em suas parcerias. Caso a empresa lançasse produtos no mercado, a situação seria diferente, com a necessidade de se atender às exigências definidas pela agência reguladora. Contudo o foco de atuação da empresa se dá na fase pré-clínica, então não há necessidade de registro.
Com relação à questão de biossegurança, é importante destacar que a Beta não possui nenhum projeto envolvendo questões de alto risco biológico. Mas, caso seja necessário no futuro, o Centro de Biotecnologia, local onde a empresa está abrigada, possui certificação que atende à legislação de biossegurança, possibilitando a execução de atividades que exijam tais cuidados.

A empresa nunca fez uso de incentivos fiscais. Por outro lado, a Beta se beneficia de subvenções econômicas, decorrentes dos editais públicos que contribuem com recursos para o financiamento das atividades da empresa. A empresa obteve recursos do Programa Primeira Empresa Inovadora (PRIME), lançado pela FINEP, e do Programa de Recursos Humanos para Atividades Estratégicas (RHAE). Complementando o financiamento público, a empresa faz uso de recursos financeiros internos, que são obtidos a partir do desempenho de suas atividades de prestação de serviços.

As políticas públicas de capacitação contribuem na execução das atividades da empresa e no desenvolvimento de parcerias, uma vez que é por meio dos recursos disponibilizados que as equipes de pesquisadores são mantidas, principalmente nos relacionamentos com a universidade e com empresa química.

\subsubsection{Análise comparativa}

A caracterização do ambiente institucional no qual as empresas pesquisadas estavam inseridas 
Quadro 4. Síntese das principais características das alianças da Beta.

\begin{tabular}{|c|c|c|c|}
\hline Parcerias & Universidade & Empresa privada & Empresa incubada \\
\hline $\begin{array}{l}\text { Descrição do } \\
\text { parceiro }\end{array}$ & $\begin{array}{l}\text { Incubadora do Centro de } \\
\text { Biotecnologia da UFRGS }\end{array}$ & $\begin{array}{l}\text { Grande empresa do setor } \\
\text { farmacêutico }\end{array}$ & $\begin{array}{l}\text { Empresa spin-off acadêmico que } \\
\text { atua na área química }\end{array}$ \\
\hline Tipo de parceria & $\begin{array}{l}\text { Acordo complexo (P\&D e } \\
\text { Manufatura) }\end{array}$ & Pesquisa e Desenvolvimento & Pesquisa e Desenvolvimento \\
\hline Papel da Beta & $\begin{array}{l}\text { Pesquisa e desenvolvimento } \\
\text { de novas moléculas } \\
\text { Prestação de serviços }\end{array}$ & $\begin{array}{l}\text { Pesquisa e desenvolvimento } \\
\text { de novas moléculas }\end{array}$ & $\begin{array}{l}\text { Pesquisa e desenvolvimento } \\
\text { biológico de novas moléculas }\end{array}$ \\
\hline Papel do parceiro & Provisão de infraestrutura & $\begin{array}{l}\text { Provisão de infraestrutura e } \\
\text { recursos financeiros }\end{array}$ & $\begin{array}{l}\text { Pesquisa e desenvolvimento } \\
\text { químico de novas moléculas }\end{array}$ \\
\hline $\begin{array}{l}\text { Recursos } \\
\text { disponibilizados }\end{array}$ & $\begin{array}{l}\text { Beta: expertise e } \\
\text { conhecimento técnico na } \\
\text { área de desenvolvimento de } \\
\text { moléculas } \\
\text { Parceiro: laboratórios }\end{array}$ & $\begin{array}{l}\text { Beta: expertise e } \\
\text { conhecimento técnico } \\
\text { Parceiro: laboratórios e } \\
\text { recursos financeiros }\end{array}$ & $\begin{array}{l}\text { Beta: expertise e conhecimento } \\
\text { na área biológica } \\
\text { Parceiro: expertise e conhecimento } \\
\text { na área química; infraestrutura } \\
\text { laboratorial }\end{array}$ \\
\hline Tipo de contrato & Formal & Formal & Formal \\
\hline $\begin{array}{l}\text { Motivação básica } \\
\text { para a parceria }\end{array}$ & $\begin{array}{l}\text { Necessidade de infraestrutura } \\
\text { para a criação da empresa }\end{array}$ & $\begin{array}{l}\text { Contribuição para o } \\
\text { desenvolvimento de novos } \\
\text { fármacos }\end{array}$ & $\begin{array}{l}\text { Necessidade de complementação } \\
\text { de recursos e conhecimento }\end{array}$ \\
\hline
\end{tabular}

demonstrou-se semelhante em todos os casos estudados. O ambiente institucional das empresas é marcado pela presença de universidades, incubadoras, empresas parceiras (clientes ou fornecedores), agências governamentais de fomento, instituições de apoio e agência reguladora (ANVISA).

A primeira característica comum que se nota é que as empresas Alfa e Beta são empresas que podem ser caracterizadas como spin-offs acadêmicos, porquanto seus fundadores são docentes de ensino superior, cujas pesquisas fomentaram o surgimento dos negócios. Essa origem comum se reflete no fato de as empresas possuírem algum tipo de relacionamento com a universidade do docente fundador.

No processo de criação e desenvolvimento de todas as organizações pesquisadas, também se destaca a participação em incubadoras de empresas. As duas empresas se beneficiaram ou se beneficiam desse relacionamento, sendo que, para a Beta, a relação com a incubadora da universidade constituiu uma de suas principais parcerias.

A análise das alianças de cada caso, com base na tipologia de Powell, Koput e Smith-Doerr (1996), permite a identificação dos principais acordos firmados pelas empresas de biotecnologia. Alianças para a realização de atividades de $\mathrm{P} \& \mathrm{D}$ se fazem presentes nas empresas Alfa e Beta. Nessa última empresa, existem parcerias nas quais as atividades de $\mathrm{P} \& \mathrm{D}$ estão inseridas dentro de acordos complexos, em que outros acordos se fazem presentes. Na Beta, o acordo complexo com a universidade também envolve atividades de manufatura.

Os acordos para suprimento e distribuição se restringem à empresa que comercializava produtos no mercado, a saber, a Alfa. O acordo de venture capitall investidor externo da Alfa envolveu o recebimento de recursos da FINEP por parte da empresa para o desenvolvimento de produto.

A análise dos relacionamentos das empresas também possibilita a identificação dos principais parceiros das empresas de biotecnologia. Em todas as empresas analisadas identificou-se algum relacionamento com uma universidade. Além disso, as alianças estabelecidas pelas empresas de biotecnologia foram desenvolvidas com empresas de diferentes setores ou empresas atuantes em diferentes etapas da cadeia produtiva.

Outro ator que merece destaque por desenvolver parceria com uma das empresas pesquisadas é a FINEP. O relacionamento com a FINEP, em muitos casos, implica a necessidade de adaptação da empresa às exigências da agência de fomento governamental, o que mostra uma clara influência do ambiente institucional-regulatório no relacionamento.

Considerando os elementos de análise do ambiente institucional-regulatório, isto é, regulação setorial (patentes e legislação de biossegurança) e fontes de financiamento, algumas semelhanças e diferenças foram verificadas nos casos estudados.

Com relação às patentes, a Beta é a única empresa em que esse aspecto está diretamente relacionado com as alianças realizadas. Como existe a possibilidade de patente em aliança de duas parcerias, na qual existe a participação da universidade, a Beta segue aquilo que é permitido pela legislação que rege as atividades da instituição de ensino no que concerne à divisão dos direitos. Na empresa Alfa, existe uma opção estratégica de não patentear produtos ou processos. 
No que diz respeito à biossegurança, na Alfa e na Beta, essa legislação não se aplica diretamente, principalmente por conta das atividades realizadas. A empresa Alfa comercializa produtos que não trazem risco biológico. Contudo, para se manter em conformidade com a legislação da ANVISA, a empresa justifica o uso de material importado para fabricação do indicador biológico. Estar de acordo com as exigências da ANVISA garante que os produtos da Alfa sejam distribuídos pela empresa parceira. Já com relação à empresa Beta, as atividades de $\mathrm{P} \& \mathrm{D}$ para desenvolvimento de moléculas se encontram em um estágio em que a legislação de biossegurança e outras regulamentações da ANVISA não se aplicam.

Quando se analisa a questão das fontes de financiamento, percebe-se que, nos dois casos, a utilização de recursos públicos foi fundamental. Enquanto a Alfa se beneficiou do apoio financeiro da FINEP, os recursos financeiros do programa RHAE e do programa PRIME foram imprescindíveis para a Beta. Os recursos recebidos pela Beta, além de possibilitarem o desenvolvimento da empresa, foram fundamentais para a manutenção de mão de obra que realiza as atividades em conjunto com as empresas parceiras.

\section{Considerações finais}

O objetivo deste artigo foi analisar a relação entre o ambiente institucional-regulatório e as alianças estratégicas colaborativas no setor de biotecnologia - segmento de saúde humana na região sul do País. Para o alcance do objetivo definido foram realizados estudos de casos em duas empresas de biotecnologia.

A caracterização do ambiente institucional no qual as empresas pesquisadas estavam inseridas demonstrou-se semelhante em todos os casos estudados. O ambiente institucional das empresas é caracterizado pela presença de universidades, incubadoras, empresas parceiras (clientes ou fornecedores), agências governamentais de fomento, instituições de apoio e agência reguladora (ANVISA).

No setor em estudo, considerando de forma ampla, a questão da regulação setorial em biotecnologia passa principalmente pela aplicação da legislação de propriedade industrial e patente (Lei 9.279/96) (BRASIL, 1996) e da legislação de biossegurança (Lei 11.105/05) (BRASIL, 2005), entre outras regulamentações e resoluções da agência reguladora do setor. É importante destacar que, à medida que as atividades de biotecnologia vão se tornando mais complexas e existe a possibilidade de produtos serem disponibilizados ao público, novas exigências regulatórias devem ser atendidas, por exemplo, testes clínicos, registro de produtos, definição de preços etc.

Por meio do estudo realizado, percebe-se que o estabelecimento de relacionamentos com os atores que compõem o ambiente institucional exige diferentes posturas das empresas. Ao se relacionar com a universidade, por exemplo, a empresa deve se adaptar ao ritmo de ação da instituição acadêmica, bem como às exigências legais atreladas a este tipo de parceria, principalmente àquelas relacionadas aos direitos de patente resultantes de atividades conjuntas de P\&D.

Nas alianças com outras empresas privadas, muitas vezes é necessário que empresas de biotecnologia atendam às regulamentações do setor para que o relacionamento aconteça, como é o caso nas parcerias que envolvem comércio e revenda de produtos biológicos. Essa situação, que ficou evidenciada no presente estudo, mostra como a regulação setorial também influencia diretamente as alianças estratégicas desenvolvidas pelas empresas de biotecnologia.

A necessidade de obter recursos financeiros, especialmente os de origem pública, mostra também o quanto o ambiente institucional influencia as alianças das empresas de biotecnologia, visto que, para obter recursos financeiros que possibilitem o seu desenvolvimento, as empresas de biotecnologia devem se adaptar às exigências e requisitos dos editais públicos.

Cabe mencionar ainda que, no caso da empresa Beta, as alianças só foram estabelecidas porque a empresa havia se beneficiado de determinado recurso financeiro público.

Por meio dos casos realizados, verificou-se que o ambiente institucional-regulatório, considerando os elementos de análise escolhidos neste estudo, está diretamente relacionado com as alianças estratégicas que são realizadas no setor de biotecnologia, segmento de saúde humana. Essa afirmação pode ser confirmada por meio das alianças que tinham como objetivo, por exemplo, obtenção de recursos financeiros. Além disso, foram identificadas alianças em que os possíveis direitos de patentes pautaram a configuração do relacionamento.

Portanto, a principal contribuição deste artigo é, com base nas evidências identificadas, mostrar que o ambiente institucional-regulatório influencia as alianças estratégicas das empresas de biotecnologia. Contudo, o tipo e o nível de influência do ambiente institucional-regulatório dependerão do tipo de atividade desempenhada pela empresa de biotecnologia, bem como das características das alianças estabelecidas com as empresas parceiras.

\section{Referências}

AUDRETSCH, D.; FELDMAN, M. Small-firm Strategic

Research Partnerships: The Case of Biotechnology.

Technology Analysis \& Strategic Management, v. 15, n. 2, p. 273-288, 2003. http://dx.doi. org/10.1080/0953732032000051154

AZEVEDO, N. et al. Pesquisa Científica e Inovação Tecnológica: A Via Brasileira da Biotecnologia. 
Revista de Ciências Sociais - DADOS, v. 45, n. 1, p. 139-176, 2002.

BIOMINAS. Parque Nacional de Empresas de Biotecnologia. Belo Horizonte: Fundação Biominas, 2001.

BIOMINAS. Estudo de Empresas de Biotecnologia do Brasil. Belo Horizonte: Fundação Biominas, 2007.

BIOMINAS. Estudo das Empresas de Biociências - Brasil 2009. Belo Horizonte: Fundação Biominas, 2009.

BORGES, I. Biotecnologia e Comércio Externo: Uma Análise da Inserção Brasileira. 2003. Dissertação de Mestrado em Ciências Econômicas)-Universidade Estadual de Campinas, Campinas, 2003.

BRASIL. Lei $\mathrm{n}^{\circ}$ 9.279, de 14 de maio de 1996. Regula direitos e obrigações relativos à propriedade industrial. Diário Oficial da República Federativa do Brasil, Poder Executivo, Brasília, DF, 15 mai. 1996. p. 8353.

BRASIL. Ministério do Desenvolvimento, Indústria e Comércio Exterior. Lei ${ }^{\circ} 11.105$, de 24 de março de 2005. Regulamenta os incisos II, IV e V do $\S 1^{\circ}$ do art. 225 da Constituição Federal, estabelece normas de segurança e mecanismos de fiscalização de atividades que envolvam organismos geneticamente modificados - OGM e seus derivados, cria o Conselho Nacional de Biossegurança - CNBS, reestrutura a Comissão Técnica Nacional de Biossegurança - CTNBio, dispõe sobre a Política Nacional de Biossegurança - PNB, revoga a Lei $\mathrm{n}^{\circ} 8.974$, de 5 de janeiro de 1995, e a Medida Provisória $\mathrm{n}^{\circ} 2.191-9$, de 23 de agosto de 2001 , e os arts. $5^{\circ}, 6^{\circ}$, $7^{\circ}, 8^{\circ}, 9^{\circ}, 10$ e 16 da Lei $n^{\circ} 10.814$, de 15 de dezembro de 2003, e dá outras providências. Diário Oficial da República Federativa do Brasil, Poder Executivo, Brasília, DF, 28 mar. 2005. Seção 1, p. 1.

BRASIL. Decreto n ${ }^{\circ}$ 6.041, de 8 de fevereiro de 2007. Institui a Política de Desenvolvimento da Biotecnologia, cria o Comitê Nacional de Biotecnologia e dá outras providências. Diário Oficial da República Federativa do Brasil, Poder Executivo, Brasília, DF, 09 fev. 2007. p. 1.

BRASIL. Ministério da Ciência e Tecnologia - MCT. Portal da Inovação. Disponível em: <www.portalinovacao. mct.gov.br>. Acesso em: 27 jul. 2011

CORDER, S.; SALLES-FILHO, S. Aspectos Conceituais do Financiamento à Inovação. Revista Brasileira de Inovação, v. 5, n. 1, p. 33-76, 2006.

CHANG, K. The Strategic Alliance of the Biotechnology Firm. Applied Economics, v. 40, p. 3089-3100, 2008. http://dx.doi.org/10.1080/00036840600994104

CHIESA, V.; TOLETTI, G. Network of Collaborations for Innovation: The Case of Biotechnology. Technology Analysis \& Strategic Management, v. 16, n. 1, p. 73-96, 2004. http://dx.doi. org/10.1080/0953732032000175517

CUNHA, C.; MELO, M. Cooperação Tecnológica em Empresas Mineiras de Biotecnologia. Revista de Administração de Empresas, v. 45, p. 60-71, 2005. Edição especial MG.

CUNHA, C.; MELO, M. A Confiança nos Relacionamentos Interorganizacionais: O Campo da Biotecnologia em Análise. RAE - Eletrônica, v. 5, n. 2, p. 1-26, 2006. http://dx.doi.org/10.1590/S1676-56482006000200009
DAHLANDER, L.; McKELVEY, M. The Occurrence and Spatial Distribution of Collaboration: Biotech Firms in Gothenburg, Sweden. Technology Analysis \& Strategic Management, v. 17, n. 4, p. 409-431, 2005. http:// dx.doi.org/10.1080/09537320500357202

DOSI, G.; ORSENIGO, L. Coordination and Transformation: an overview of structures, behaviours and change in evolutionary environments. In: DOSI, G. et al. (Ed.). Technical Change and Economic Theory. London: Pinter Publishers, 1988.

EBERS, M.; POWELL, W. Biotechnology: Its Origins, Organization and Outputs. Research Policy, v. 36, p. 433-437, 2007. http://dx.doi.org/10.1016/j. respol.2007.04.001

EINSENHARDT, K. Building Theories from Case Study Research. Academy of Management Review, v. 14, n. 4, p. 532-550, 1989

ESTRELLA, A. Aprendizagem interorganizacional via parcerias estratégicas colaborativas na indústria brasileira de biotecnologia, segmento de saúde humana. 2008. Dissertação (Mestrado em Administração de Empresas)-Universidade Presbiteriana Mackenzie, São Paulo, 2008.

FIGUEIREDO, L.; PENTEADO, M. I.; MEDEIROS, P. Patentes em Biotecnologia - Patenteamento em Biotecnologia Agropecuária: Cenário Brasileiro. Biotecnologia Ciência e Desenvolvimento, v. 9, n. 36, 2006.

JUDICE, V.; BAETA, A. Modelo Empresarial, Gestão de Inovação e Investimentos de Venture Capital em Empresas de Biotecnologia no Brasil. Revista de Administração Contemporânea, v. 9, n. 1, p. 171-191, 2005. http:// dx.doi.org/10.1590/S1415-65552005000100009

KAISER, R. Multi-level Science Policy and Regional Innovation: The Case of the Munich Cluster for Pharmaceutical Biotechnology. European Planning Studies, v. 11, n. 7, p. 841-857, 2003. http://dx.doi. org/10.1080/0965431032000121373

LAVILLE, C.; DIONNE, J. A Construção do Saber: Manual de metodologia da pesquisa em ciências humanas. Porto Alegre: ARTMED, 1999.

MAÇANEIRO, M. B.; CHEROBIM, A. P. Fontes de Financiamento à Inovação: Incentivos e Óbices às Micro e Pequenas Empresas - Estudo de Casos Múltiplos no Estado do Paraná. Organização \& Sociedade, v. 18, n. 56, p. 57-75, 2011.

ORGANISATION FOR ECONOMIC CO-OPERATION AND DEVELOPMENT - OECD. Biotechnology Statistics 2009. Paris: OECD, 2009.

OLIVER, A. Strategic Alliances and the Learning Life-cycle of Biotechnology Firms. Organization Studies, v. 22, n. 3, p. 467-489, 2001. http://dx.doi. org/10.1177/0170840601223004

PANGARKAR, N. Determinants of Alliance Duration in Uncertain Environments: The Case of Biotechnology Sector. Long Range Planning, v. 36, p. 269-284, 2003. http://dx.doi.org/10.1016/S0024-6301(03)00041-4

POSSAS, C. Inovação e Regulação na Biotecnologia: Desafios para a Integração Intercontinental. In: CONFERÊNCIA BRASIL E UNIÃO EUROPÉIA 
AMPLIADA, 2004, Rio de Janeiro. Anais... Rio de Janeiro: UFRJ, 2004. PMid:15233934.

POWELL, W.; KOPUT, K.; SMITH-DOERR, L. Interorganizational Collaboration and the Locus of Innovation: Networks of Learning in Biotechnology. Administrative Science Quarterly, v. 41, n. 1, p. 116-145, 1996. http://dx.doi.org/10.2307/2393988

PREVEZER, M.; TOKER, S. The Degree of Integration in Strategic Alliances. Technology Analysis \& Strategic Management, v. 8, n. 2, p. 117-133, 1996. http://dx.doi. org/10.1080/09537329608524239

ROIJAKKERS, N.; HAGEDOORN, J. Inter-firm R\&D Partnering in Pharmaceutical Biotechnology since 1975: Trends, Patterns and Networks. Research Policy, v. 35, p. 431-446, 2006. http://dx.doi.org/10.1016/j. respol.2006.01.006

SILVEIRA, J.M.; POZ, M.E.; FONSECA, M.A. Requerimentos Institucionais para o Incentivo ao Desenvolvimento de Novas Empresas de Biotecnologia no Brasil. In: SIMPÓSIO DE GESTÃO DA INOVAÇÃO TECNOLÓGICA, 22., 2002, Salvador. Anais... São Paulo: PGT/USP, 2002.
SILVEIRA, J. et al. Evolução Recente da Biotecnologia no Brasil. Campinas: Instituto de Economia/ UNICAMP, 2004. (Texto para Discussão, n. 114).

SCOTT, R. Institutions and Organizations: Ideas and Interests. Los Angeles: SAGE Publications, 2008.

VALLE, M. O Sistema Nacional de Inovação em Biotecnologia no Brasil: possíveis cenários. 2005. Tese (Doutorado em Política Científica e Tecnológica)Universidade Estadual de Campinas, Campinas, 2005.

VÁZQUEZ, E. G. M.; MARTÍN, J. A. J.; MASCAREÑAS, J. Strategic alliances as a mechanism for wealth creation in the biopharmaceutical industry: an empirical analysis of the spanish case. Journal of Commercial Biotechnology, v. 12, n. 3, p. 229-236, 2006. http://dx.doi.org/10.1057/ palgrave.jcb.3040171

WILLIAMSON, O. The Institutions and Governance of Economic Development and Reform. The World Bank Research Observer, 1994.

ZHANG, J.; BADEN-FULLER, C.; MANGEMATIN, V. Technological knowledge base, R\&D organization structure and alliance formation: evidence from biopharmaceutical industry. Research Policy, v. 36, p. 515-528, 2007. http://dx.doi.org/10.1016/j. respol.2007.02.015 